
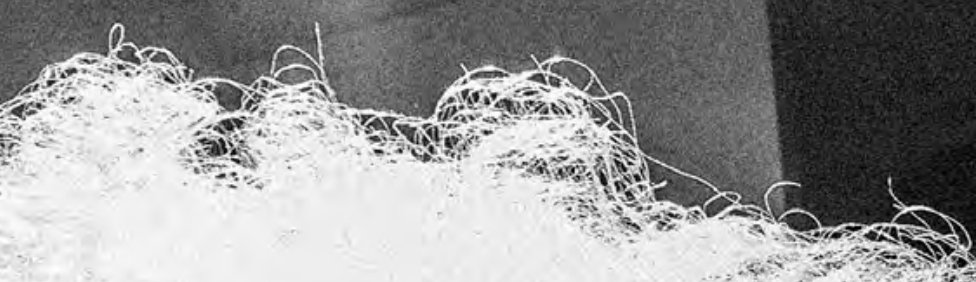

\title{
Reflexões sobre a
} profissão de modelo: a categoria do exótico na moda e na Antropologia

Reflections on the model profession: the exotic category in Fashion and Anthropology

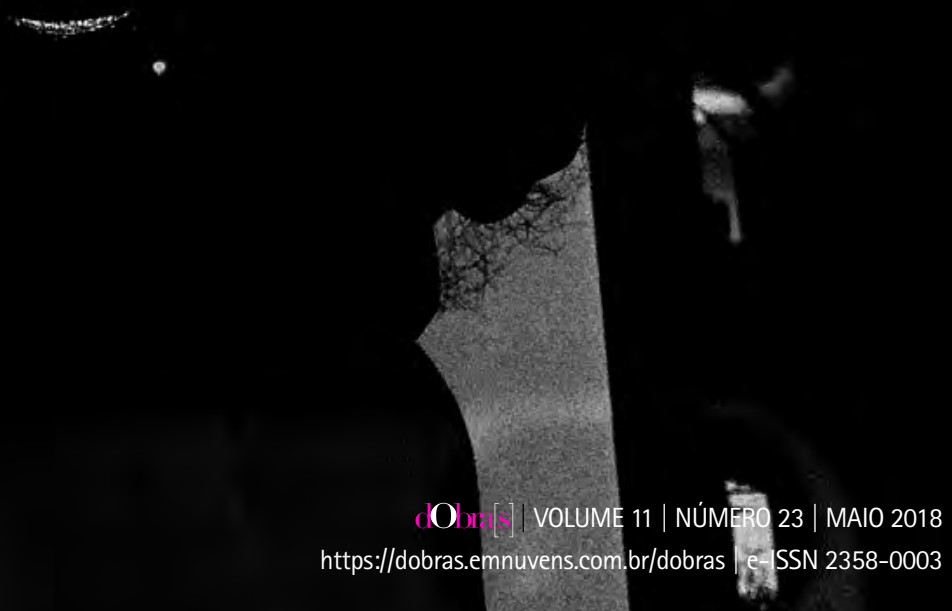




\section{[LARA VIRGÍNIA SARAIVA PALMEIRA]}

Doutoranda em Antropologia Social pelo Museu Nacional - Universidade Federal do Rio de Janeiro (UFRJ).

\section{E-mail: larasaraiva85@gmail.com}

[resumo] Este artigo tem por objetivo analisar como a categoria do exótico é abordada no campo da moda e nos escritos antropológicos. Inicialmente, procurou-se tratar de questões relativas à profissão de modelo, a construção histórico-social da supervalorização e da padronização corporal e, posteriormente, analisar como o exótico apareceu nesse contexto. A questão racial surgiu atrelada ao termo em evidência nos exemplos dos jovens modelos africanos presentes no campo. Assim, tal conceito nos auxilia a refletir sobre importantes relações de poder existentes nesse universo subscritas por meio I83 da linguagem. Os dados baseiam-se em uma pesquisa etnográfica realizada durante 2012 e 2013 em uma agência de modelos na cidade de Fortaleza (CE).

\section{palavras-chave}

\section{moda; modelo; exótico.}

[abstract] This article tries to discuss how the category of "exotic" is approached in the field of fashion and anthropological writings. Initially, it was tried to approach questions related to the profession of model, the socio-historical construction of the overvaluation and corporal standardization and, later, to analyze how the exotic appeared in this context. The racial question comes from tied to the term in evidence through the examples of the younger's African models present in the field. Thus, this concept helps us to reflect on important relations of power, present in this universe subscribed through language. The data are based on an ethnographic survey made on Fortaleza -CE during 2012 and 2013 at a modeling agency.

[keywords] fashion; model; exotic. 


\section{Introdução}

Este artigo tem por objetivo analisar como a categoria do exótico é abordada no campo da moda, bem como é referenciada nos escritos antropológicos e por representantes da militância negra. Nesse sentido, ressalta-se o uso de três diferentes tipos de discurso originados de campos diferentes, mas que convergem sobre o mesmo tema, demonstrando a importância de articular um diálogo entre eles, diferenciando-os da maneira mais clara possivel.

A primeira seção do artigo destina-se a pensar como a figura do exótico foi construindo-se e problematizando-se na literatura antropológica. Recorre-se, nesse sentido, ao início do pensamento antropológico ao analisar como a figura do exótico estava presente na figura do outro; mostramos como as reflexões foram amadurecendo ao longo do tempo e como os estudos culturais passaram a problematizar o outro - o selvagem, o exótico, o nativo - quando a Antropologia consolidou-se em paises periféricos.

Em seguida, como o exótico foi mostrando-se no campo da moda, além de recapitular algumas das principais caracteristicas que alicerçam a profissão de modelo e nos auxiliam a entender as bases em que a categoria do exótico se apoia. Com esse objetivo, utilizamos como base o livro Profissão modelo: em busca da fama, da Editora Senac, no qual Margareth Libardi (2004) realiza uma compilação sobre as experiências que teve enquanto modelo e produtora de filmes publicitários em São Paulo. Além de tal fonte, resgatamos as normas e prescrições que se encontram na agência de modelos pesquisada, a Belas Modelos. Assim, procurou-se abordar questões relativas à profissão de modelo e a construção histórico-social da supervalorização e da padronização corporal.

Por fim, foram tecidos comentários sobre como a questão racial apareceu atrelada ao exótico e como a violência contra o corpo feminino negro resguarda uma direta ligação com essa problemática. Utilizam-se autoras que refletem sobre a condição da mulher negra em instâncias diferentes, seja na literatura, seja nos escritos filosóficos ou em artigos de jornais.

A pesquisa de campo em que este artigo se baseia foi realizada durante os anos de 2012 e 2013 em uma agência de modelos da cidade de Fortaleza (CE), denominada Belas Modelos. A metodologia utilizada foi a observação participante, característica da Antropologia, com destaque para as entrevistas semiestruturadas com os profissionais da agência, além da observação sistemática de eventos de moda e do cotidiano da agência. Os profissionais 
cujas entrevistas estão citadas neste artigo são Roberto, diretor e proprietário da agência, entrevistado em 21/09/2012, e Antônio, gerente, entrevistado em 17/10/2012.

Em sintese, vale ressaltar que as nomenclaturas aqui utilizadas para se referirem ao campo e aos sujeitos desta pesquisa são pseudônimos utilizados com o objetivo de resguardar a identidade dos interlocutores.

\section{A categoria do exótico na Antropologia}

Como afirma Peirano (1999), durante longo tempo a Antropologia foi definida pelo exotismo e pela distância geográfica, que também se traduzia em termos culturais, do seu objeto de estudo. A tradição sistematizada por Bronislaw Malinowski (1984), no início do século XX, na então nascente antropologia social inglesa, denominada de observação participante, advoga que a familiaridade com o nativo e a capacidade de participar do seu universo são condições prévias para a investigação antropológica. Assim, vários intelectuais europeus dotados do estilo malinowskiano (terno branco impecável acompanhado de chapéu igualmente imaculado) deslocavam-se para regiões mais longínquas, inimagináveis e até então tidas como desconhecidas para realizarem suas extensas pesquisas de campo.

Como bem afirma Godelier (1992), a Antropologia nasce marcada por estigmas, como uma disciplina que se dedicaria ao conhecimento de povos ou grupos sociais (os outros) que, na visão dos pesquisadores (nós) - e esta dicotomia nós versus outros permanecerá sempre presente nas discussões antropológicas -, são classificados como atrasados, menos desenvolvidos, em termos sociais, culturais, políticos e econômicos. Assim, os outros grupos sociais foram rapidamente colocados no início de uma escala linear progressiva. Isso porque a Antropologia nasce em um contexto colonialista de expansão, e os efeitos da teoria evolucionista ainda ecoavam com bastante força no contexto europeu, inquestionavelmente sob a liderança da Grã-Bretanha. Assim, afirma Godelier (1992):

Nasceu pouco a pouco, da necessidade experimentada no Ocidente de conhecer melhor dois campos da realidade que no início eram totalmente divorciados um do outro: de um lado os povos da África, da América pré-colombiana e da Ásia que a Europa estava descobrindo e progressivamente submetendo a seu comércio ou ao poderio de suas armas. Em todo lugar, para governar, comerciar ou evangelizar, militares, missionários e funcionários eram obrigados, mais cedo ou mais tarde, a dedicar-se ao estudo das línguas - em sua maioria não escritas - e à observação dos costumes desses povos, quando mais não fosse para erradicá-Ios. (GODELIER, 1992, p. 2)

Nesse sentido, estava claro quem seriam os outros: um mundo recém-colonizado, marcadamente não europeu, que se encontrava em um violento processo de dominação. Logo, constituem-se os primeiros exóticos da tradição antropológica: os selvagens'. 
Nas palavras do antropólogo haitiano Michel Trouillot (2003), a figura do selvagem, assim como o papel conceitual e o local epistemológico que ocupa, (que o autor denomina de "nicho do selvagem"), foi herdada e nunca verdadeiramente questionada pelo pensamento antropológico hegemônico. Entretanto, alguns movimentos ocorridos no continuum histórico, bem como no próprio amadurecimento das reflexões antropológicas, resultaram em mudanças nessa "geografia da imaginação" que haveria engendrado o Ocidente e a antropologia disciplinar, nas palavras de Trouillot (2003).

Assim, para o haitiano, a relação da antropologia com o colonialismo começou a ser evidenciada há pouco mais de meio século. Situando-se em uma escala temporal, destacam-se as décadas de 1960 e 1970 como fundamentais para entender tais processos de descolonização epistêmica, o que não impede que, anterior a esse período, não tenham havido escritos que convergissem nessa mesma direção. No plano histórico-político, destaque para o triunfo dos movimentos de libertação nacional na África, na Ásia e na Oceania. No plano das ideias, os movimentos do marxismo, dos feminismos e dos estudos de etnicidade deram contribuições significativas.

Tais processos desconstrutivos suscitaram problematizações em que os regimes de representação da alteridade, da maneira que foram construídos nas antropologias hegemônicas, passaram a ser revistos. Os sujeitos colonizados, antes considerados os outros, os selvagens, passaram a reivindicar sua voz e a criticar a maneira como as histórias sobre eles foram construídas. 0 exótico estava sendo problematizado, mas, dessa vez, não era apenas objeto, era sujeito também. Tal cenário desencadeou, principalmente no âmbito americano, no movimento pós-modernista da Antropologia. Entretanto, é outra linha de estudo que aqui se detalha melhor: os estudos culturais caracterizados como pós-coloniais.

De acordo com Silva e Freire (2013), muitos dos autores classificados como pós-coloniais podem ser associados a uma proposta teórica e multidisciplinar conhecida como estudos culturais. Apesar de estarem concentrados no Centre for Contemporary Studies (CCS) da University of Birmingham, os estudos alinhados a essa proposta surgiram em várias partes do globo. Segundo os autores citados, a primeira geração dos estudos culturais dedicou-se à questão de classe, mais especificamente à reconstrução histórica da classe operária inglesa. A segunda geração discutiu questões de classe aliadas a outros importantes marcadores sociais, como raça, gênero e etnia. Nessa geração, encontram-se presentes autores como Homi Bhabha e Stuart Hall.

Assim, por meio do processo de descentralização da Antropologia com a sua consolidação em países periféricos, esses autores passaram a questionar a autoridade etnográfica, a construção do outro e a etnografia como práxis (SILVA e FREIRE, 2013). Inaugurando novas maneiras de olhar os sujeitos subalternos, Bhabha e Hall (indiano e jamaicano, respectivamente) passaram a verificar como a maneira eurocêntrica de construção do conhecimento direcionava as produções antropológicas e passaram a construir novos vocábulos 
e epistemes a partir da própria realidade que vivenciaram. 0 movimento pela independência da Jamaica e a Segunda Guerra Mundial despertaram em Hall uma consciência histórica e geográfica que marcaria seus escritos sobre a diáspora caribenha. Já Bhabha pensou, em termos culturais, os diversos modos como os povos colonizados resistiram ao poder dos colonizadores, propondo uma teoria do hibridismo cultural na tentativa de elucidar as ligações entre colonialismo e globalização.

Dessa forma, ratificam Silva e Freire (2013):

0 momento histórico de independência e a produção antropológica no dito terceiro mundo abriu possibilidades para críticas ao modo como a antropologia operava fora das metrópoles, surgindo espaços problemáticos de produção etnográfica que rompiam com a dicotomia antropólogo-nativo, e criticando o próprio termo nativo. Isso possibilitou colocar a questão de como os trabalhos monográficos interpretavam e representavam 0 outro, problematizando, assim, a própria noção de alteridade. (SILVA; FREIRE, 2013, pp. 50-51)

Essas rápidas notas acerca da trajetória de termos como selvagem, nativo e o próprio exótico têm como intenção mostrar como eles sofrem transformações e são analisados constantemente, o que os torna polissêmicos dependentes de uma contextualização para serem melhor apreendidos. Mais adiante, compreender-se-á como o termo exótico é construído no campo da moda por meio de seus discursos e práticas, ademais como pode ser relacionada à questão racial e de gênero, fortemente presentes no campo de pesquisa.

\section{A categoria do exótico no campo da moda}

Antes de entrarmos especificamente na questão do exótico no campo da moda estudado, vale sublinhar alguns pontos importantes que recapitulam um pouco da profissão de modelo, bem como suas particularidades. Afinal, sobre o que se trata a profissão de modelo?

Sem dúvida, uma das principais caracteristicas dessa profissão é a valorização do corpo, assim como a construção de um padrão de beleza. Nesse sentido, a categoria do exótico aparece para designar algo que destoa desse padrão, mas, por alguma(s) caracteristica(s) idiossincrática(s), esse traço pode ser valorizado.

Voltando às questões corporais, o corpo de uma modelo é uma de suas principais preocupações na medida em que se figura como o principal passaporte para ser uma profissional. Em seu primeiro contato com esse mundo, suas classificações e exigências, o corpo é o primeiro a ser avaliado por um conjunto de especialistas que enxergam nele um potencial para as passarelas, as lentes fotográficas ou ambos. 
Para compreender como o corpo adquiriu essa dimensão na moda, especificamente na atividade das modelos, é necessário compreender as relações do indivíduo com o corpo, bem como suas mudanças no decorrer do tempo. Nesse sentido, é consenso entre os autores que versam sobre a temática que a segunda metade do século XX representou uma significativa mudança nessas relações. Assim, tal período é fundamental para entender essa preocupação, como afirma Le Breton (2006):

No final dos anos 1960, a crise da legitimidade das modalidades físicas da relação com o homem com os outros e com o mundo amplia-se consideravelmente com o feminismo, a "revolução sexual", a expressão corporal, o body art, a crítica do esporte, a emergência de novas terapias, proclamando bem alto a ambição de se associar somente ao corpo, etc. Um novo imaginário do corpo, luxuriante, invade a sociedade, nenhuma região da prática social sai ilesa das reivindicações que se desenvolvem na crítica da condição corporal dos atores. (LE BRETON, 2006, p. 9)

A intensificação da preocupação com o corpo está ligada à história da moda, conforme afirma Castro (2007). Com o passar do tempo, a flexibilidade no vestuário prevalece sobre a rigidez, e o que se pode perceber hoje é que o século XX foi marcado pelo desnudamento das pessoas do Ocidente, mais enfaticamente do corpo das mulheres. Ou seja, as roupas e as suas formas teriam se tornado cada vez mais flexíveis e, em muitos casos, principalmente se comparamos as roupas de hoje com certos modelos de antigamente, o nu aparece cada vez mais. Já no século XXI não parece estar sendo diferente.

Discorrer sobre um padrão corporal no campo da moda mostra-se uma tarefa complexa no sentido de que as suas regras podem parecer claras e rígidas, mas, em determinadas ocasiões, maleáveis e contornáveis. Para entender mais essa complexidade, recorre-se à diferença existente entre as modelos fashion e as modelos comerciais: as primeiras obedecem a critérios mais rígidos devido à lógica estética na qual devem se inserir; já as segundas possuem uma maior maleabilidade dessa medida (critérios mais frouxos e relativos).

0 principal e mais evidente traço da modelo fashion é a magreza. Como a sua exposição é completa, ao vivo e na frente do público, sua imagem deve ser a de um corpo esguio e perfeito. A altura também é um ponto importantíssimo. Geralmente, a altura ideal de uma modelo fashion é entre 1,73 m e 1,80 m. É claro que existem modelos mais baixas, no entanto, se a jovem deseja ser uma top mode $l^{2}$ com uma carreira internacional, deve atender essa exigência. As medidas também são importantes. Quanto mais perfeita a modelo, melhores serão suas chances profissionais. As proporções ideais são: 1,77 m de altura, $89 \mathrm{~cm}$ de busto, $89 \mathrm{~cm}$ de quadril e $60 \mathrm{~cm}$ de cintura ${ }^{3}$.

Sobre a questão da magreza no início da profissão, muitas modelos afirmaram a Bonadio (2004) que, nos anos 1960, não havia essa obsessão pela magreza, não havia mulheres passando fome, não se falava em regime, enfim, 
não existia essa necessidade tão intensa que se tem hoje de estar magra. $\mathrm{A}$ autora concluiu que essa tolerância em relação aos cuidados com a aparência era uma consequência da pressão sobre o comportamento social das modelos da Rhodia. Era proibido para as modelos terem vida própria: elas não podiam sair, passear e manter relacionamentos afetivos. A rígida vigilância sobre o comportamento das modelos tinha, provavelmente, uma razão, segundo a autora: resguardar a dignidade, o status das profissionais e, consequentemente, a marca por elas representada. As modelos não deveriam ser mulheres difamadas, já que, na época, as mulheres que eram modelos eram consideradas prostitutas.

Outro ponto para salientar é a questão da idade das modelos. Quanto menos idade tiver, mais chances ela tem de se tornar bem-sucedida. 0 porquê dessa entrada precoce parece ter duas razões: a primeira pelo fato da juventude ser um valor imprescindivel na sociedade que cultua a aparência e 0 antienvelhecimento, segundo Lipovetsky (2000). A segunda porque os agentes podem criar expectativas quanto às transformações no corpo das modelos.

No entanto, diante de um padrão de beleza tão específico, como lidar com uma quantidade imensa de jovens que não se enquadra nele e que, ainda assim, almeja um dia se tornar modelo? 0 discurso daqueles que trabalham com o setor é de que o mercado de trabalho para modelos tem espaço para uma numerosidade de tipos físicos, idades etc. No entanto, é tarefa da modelo definir e encarar seu tipo físico, descobrindo o que ela tem de bom para mostrar e o que tem de ruim para esconder ou mudar a fim de saber em qual lugar se encaixa. Nesse sentido, uma frase de Libardi (2004) publicada no seu manual parece ser bem interessante para ilustrar como cada tipo físico tem seu papel bem definido:

$\mathrm{Na}$ carreira de modelo, a gostosa posa para a revista masculina, a magérrima vai para Milão e a graciosa, para o Japão. Assim é que são as coisas. Cada um na sua. Imagine a Tiazinha desfilando alta costura em Milão e a Gisele Bündchen rebolando de espartilho num programa de tevê. Não combina! (LIBARDI, 2004, p. 97)

Tal assertiva é bastante reveladora, pois cada uma das atividades (posar para uma revista masculina ou desfilar em Milão ou em Tóquio) tem significado e valor diferentes, ocupa um lugar diferenciado na hierarquia que demonstra uma série de valores. A maioria das que desejam ser modelo fashion não almeja aparecer em capa de revista masculina, não deseja ser gostosa. Pelo contrário, no campo da pesquisa, os discursos revelam que a vulgaridade e a sensualidade são evitadas, por exemplo, quando o fotógrafo da agência não classificou como uma boa foto aquela em que a modelo empinava muito o bumbum.

Quanto à diferença entre desfilar em Milão e em Tóquio, a segunda opção é considerada um mercado secundário no segmento fashion. As modelos vão 
para lá para amadurecer e acumular dinheiro, mas, em termos de status, Milão é considerado um dos principais centros de moda do mundo, assim como Nova York e Paris. Pode-se observar ainda nessa valoração uma espécie de lógica colonizadora que, como em outros segmentos, privilegia a Europa (e os Estados Unidos) em detrimento de outros paises classificados como Terceiro Mundo. Mais adiante, retoma-se tal lógica colonizadora, exemplificando-a com casos encontrados na pesquisa etnográfica e como ela opera classificando algumas modelos como exóticas.

Quanto ao cenário local, na agência de modelos cearense que figurou como campo de pesquisa, a Belas Modelos, não foram encontradas modelos exageradamente magras. Pelo contrário, havia muitas modelos consideradas acima do peso para a passarela. Esse foi um dos dados que despertou atenção: o fato de que a Belas Modelos não seguiria rigidamente os critérios acima descritos. Roberto, diretor da agência e principal responsável pelo casting, costuma advertir as modelos que estariam gordinhas, mas tal fato não é uma obsessão, uma condição imprescindivel para agenciá-las e para elas realizarem trabalhos. Aqui, cabe ressaltar que a agência de modelos em questão tem como principal público estabelecimentos comerciais que podem ser enquadrados nas classes $C$ e D. Os trabalhos mais recorrentes realizados pela Belas Modelos consistem em ações publicitárias para os mais variados clientes (desde óticas e prestadoras de serviços odontológicos até campanhas publicitárias de vestuário e/ou calçados). Ou seja, tais empresas e também seus clientes não exigem modelos com 1,75 m de altura e magérrimas. Portanto, agências como a Belas Modelos procuram adequar seu trabalho aos tipos físicos locais por um lado e, por outro, à lógica estética dos anunciantes - de certa forma, fazendo uma releitura dos padrões da moda nos seus próprios termos e significados simbólicos. É o que Martinez (2009) comenta ao falar sobre como a moda opera como um sistema de status que repercute em todo o campo.

Ainda quanto aos tipos físicos locais, remete-se a outra questão referente às características do povo nordestino e do sulista. Ao contrário do Nordeste, a região Sul é a principal exportadora de modelos do país. É onde podemos encontrar pessoas mais adequadas aos padrões de beleza exigidos na moda e que também se assemelham aos padrões de beleza europeus: mulheres altas, loiras, com cabelos lisos e olhos claros. Pode parecer uma contradição em relação aos dados citados anteriormente, nos quais afirma-se que todos os tipos físicos podem ser contemplados no mundo da moda. Essa contradição realmente existe na medida em que a moda abre espaço para pessoas dos mais variados tipos físicos, mas as chances de galgar sucesso, pelo menos no seu espaço mais nobre e celebrado, ou seja, o seu lado fashion, são restritas somente àquelas que se enquadram no perfil mais exigente, que já foi descrito acima. Nesse sentido, o tipo físico dos nordestinos não coincide com o dos sulistas. A estatura do povo cearense, por exemplo, não é das mais altas do país, o que não corresponde ao padrão exigido pela moda. Logo, de acordo com tais exigências, no Estado, é difícil encontrar modelos que se adequem aos mais exigentes padrões da moda. 
Entretanto, existem as exceções, vide modelos nordestinas que alcançaram sucesso e fama internacionais, como Fernanda Tavares (potiguar) e Adriana Lima (soteropolitana).

0 que se pretende afirmar, portanto, é que os tipos físicos dos brasileiros resguardam diferenças regionais importantes. Além disso, existe um estereótipo de que os nordestinos não são pessoas bonitas. Conclui-se a partir de piadas com o tema da aparência dos nordestinos divulgadas pelo pais afora e corroboradas, indiretamente, por Libardi (2004). Em seu livro, ela fala de cada região do país e como é o mercado de modelo. Sobre o Sul, ela afirma que lá é mais fácil encontrar o biótipo mais aceito na moda e na publicidade, pois o fenômeno da imigração italiana e alemã teria colaborado para a fabricação de gente bonita.

Além da beleza dessas modelos, o fato de serem bem-educadas, determinadas e disciplinadas justificaria seu sucesso no mercado. Enquanto isso, no Nordeste, "dessa região surgem modelos bonitos, alguns bem exóticos" (LIBARDI, 2004, p. 161).

Para contrabalançar o julgamento negativo e preconceituoso, a autora atenta para a questão de o Nordeste estar situado próximo do grande centro de moda e de publicidade do país, a região Sudeste, mais especificamente São Paulo. Quanto mais longe se está desse centro, pior, segundo a autora. São Paulo está sempre presente nas conversas de Roberto com as modelos, principalmente depois do contato que ele estabeleceu com uma agência de Campinas. Segundo ele, o nivel das modelos de lá é muito diferente do nivel das do Ceará. "Lá, a coisa é séria, as meninas trabalham de verdade", segundo o diretor. Ainda, segundo Roberto, em São Paulo, as cearenses são bem pagas, pois os agentes e o mercado estariam cansados de rostos paulistanos. Então, quando chega uma modelo do Nordeste bonita, logo ela é contratada para bons trabalhos.

Ressalta-se, nesse sentido, a dicotomia centro-periferia que se mostrou muito clara também no mundo da moda. 0 centro seria a região Sudeste-Sul, enquanto a periferia consiste no restante do Brasil. As modelos nordestinas são exóticas por se destacarem das demais, mesmo sem seguir fielmente os padrões de beleza europeus.

E quando o exótico apareceu no campo de pesquisa? "Exótico é que é diferente. É uma coisa assim que você vê: Nossa, como é lindo, é linda! Bem diferente que se você vê assim: ah, vai ganhar muito trabalho, e ganha!" (Diário de campo, 17 de outubro de 2012). Essa foi a definição de Antônio, gerente da agência, sobre o referido termo. Ela ficou mais clara quando se observou quais jovens da Belas Modelos eram classificados como exóticos: os modelos africanos.

Devido ao convênio da Universidade Federal do Ceará (UFC) com universidades africanas, muitos jovens oriundos de várias partes da África, tais como 
Cabo Verde e Guiné-Bissau, residem em Fortaleza com o objetivo de realizar seus estudos universitários. Nesse sentido, alguns procuram atividades laborais na cidade a fim de ganhar dinheiro e instalar-se com mais conforto na capital. Uma dessas atividades é desfilar e trabalhar como modelos em campanhas publicitárias. A agência, em 2013, tinha três modelos africanos, duas mulheres e um homem, incluindo Ana Braga, a vencedora do concurso anual da agência, o Belas Modelos Ceará 2012. Na realidade, o fato dos modelos serem negros, reforçado pela sua origem africana, confere-lhes autenticidade e isso faz com que eles ganhem muitos trabalhos, segundo Antônio. Assim, no caso explicitado acima, vemos de que maneira o mercado da moda se apropria dos modelos exóticos para a obtenção de lucro: aquilo que é diferente é positivado, supostamente colocado como uma vantagem comercial.

Sobre a questão do negro no mundo da moda, Martinez (2003) afirma que o mercado começou a absorver modelos negras a partir da metade da década de 1960, porém de forma relativamente pontual. Retomando Libardi (2004), 0 mercado absorve poucas modelos negras. Os motivos que a autora alega para não ter tantos negros no mundo da moda e no publicitário são vários. Segundo Libardi (2004), que trabalha com produção de elencos, a publicidade reflete o que acontece na sociedade, ela tenta transmitir uma imagem de sucesso, beleza, glamour e felicidade e essa imagem de modelo de beleza e de sucesso é a do branco. Os brancos também são maioria no mercado consumidor e é óbvio que as campanhas publicitárias são feitas para quem compra mais. Por I92 ] isso, os negros têm espaço garantido em nichos específicos, ou seja, em campanhas publicitárias de produtos para negros, como propagandas de xampus e maquiagem. Dessa forma, o lugar do negro na moda e na publicidade é mais do que restrito, já que eles aparecem somente nos mesmos lugares segregados que ocupam na sociedade dominada pela população branca. "Os negros estariam conquistando espaço gradativamente" (p. 130), "o preconceito racial está cada vez mais distante da profissão de modelo" (p. 128), "tem negro que faz mais sucesso que muito branco" (p. 128), são algumas das frases que Libardi (2004) utiliza para contrabalançar sua opinião, no entanto, o que podemos perceber analisando o seu discurso é que a autora acaba por reproduzir um discurso racista, além de não criticar essa desigualdade, aceitando-a aparentemente como incontornável até que as pessoas negras sejam equivalentes ou prevalecentes na distribuição do mercado de consumo por cor.

Para finalizar a questão racial e mostrar como esta se relaciona com o termo exótico, foi trazido outro tipo de discurso - o de militantes negras - para auxiliar a compreender melhor essa complexa relação e como ela é construída no que tange ao sexo feminino $0^{4}$.

Para Jarid Arraes (2013), uma das autoras do blog Blogueiras negras, a hipersexualização do corpo feminino negro, enfatizando traços como os de excêntricas e diferentes do convencional, promove uma falsa valorização das garotas negras, que deixam de ser completamente rejeitadas para se tornarem aceitas desde que seus corpos sejam submetidos à exotificação racial. Assim, tais traços de violência passam despercebidos, disfarçados em 
formas de elogios. Desse modo, a autora reflete: até que medida essa suposta valorização não passa de uma falsa democratização em vez de uma efetiva promoção da igualdade de traços e beleza diferentes, sem colocá-las, necessariamente, em escalas de valoração?

A questão da violência contra o corpo feminino negro é ainda historicizada pela autora clássica Angela Davis (ativista e militante negra), em sua obra Mulheres, raça e classe (2013), em que a autora defende a ideia de que a escravidão forjou um novo tipo de feminilidade para a mulher negra em contraposição ao que foi construido para a mulher branca, que seria o de frágil, submissa, restrita aos afazeres domésticos, enquanto o homem branco trabalhava e se constituia como provedor do lar.

Davis (2013) afirma que as caracteristicas que as mulheres negras reconhecem em si mesmas não são resultado da condição feminina em si, mas da condição histórica e racial de um passado escravocrata. 0 trabalho ocupou muito mais tempo na vida das mulheres negras do que na das brancas. $\mathrm{Na}$ condição de escravas, o trabalho compulsório ao qual essas mulheres eram submetidas ofuscou qualquer outro aspecto da existência feminina. Até mesmo a valorização da maternidade, caracteristica do século XIX, e vista de outra forma na lógica escravocrata quando o comércio de escravos foi reduzido, não teria atingido as negras. Assim, desconstruindo a universalidade em torno da categoria mulher, Davis (2013) procura caracterizar a mulher negra por meio do seu passado histórico escravocrata.

A ativista afirma ainda que a mulher negra foi submetida à mesma lógica de dominação que o homem negro: o mesmo tempo de trabalho, a mesma produtividade, a mesma intensidade de esforço e de castigos. Entretanto, uma diferença seria crucial: a sistemática violência do corpo feminino. Sobre esse fato, sublinha a autora:

Neste sentido, a opressão para as mulheres era idêntica à opressão para os homens. Mas as mulheres também sofreram de maneiras diferentes, porque eram vítimas de abuso sexual e outras barbaridades de maus tratos que apenas podem ser infligidas às mulheres. Os comportamentos dos donos de escravos para as mulheres escravas eram: quando era rentável explorá-las como se fossem homens, sendo observadas, com efeito, sem distinção de género, mas quando elas podiam ser exploradas, castigadas e reprimidas em formas ajustadas apenas às mulheres, elas eram fechadas dentro do seu papel exclusivo de mulheres. (DAVIS, 2013, p.11)

Assim, conclui Davis (2013), das mulheres escravas era exigida uma performance masculina por causa do seu trabalho, que deveria ser semelhante ao do homem. Logo, as mulheres negras foram profundamente afetadas pelas suas experiências durante a escravatura, assumindo qualidades que não eram das mais comuns àquelas relegadas à natureza feminina pela ideologia do século XIX. 
Os escritos de Davis mostram-se fundamentais para compreender como a questão da violência esteve desde cedo presente na condição histórica da mulher negra e como as diversas manifestações dessa relação continuam vivas até mesmo no plano da estética e na nossa construção sobre o que é belo. Sobre tal fato, Ribeiro (2017) comenta, em uma de suas colunas na Carta Capital, como o racismo tem um papel preponderante na construção desses padrões. Discorre a filósofa:

Olhem as revistas. Liguem a tevê. Qual a "mulher ideal"? Quantas de nós foram preteridas pelo simples fato de ser negras? Como falar em gosto pessoal, quando a esmagadora maioria pretere mulheres negras? Como falar em "escolha do individuo", quando essas escolhas não nos escolhem? (RIBEIRO, 2017, s/p)

Ribeiro (2017) ainda afirma categoricamente que mulheres negras não são animais raros para serem consideradas exóticas e cita o exemplo de Sarah Baartman, a Vênus de Hotentote, exposta por toda a Europa em teatros e feiras durante o século XVIII até o ano de 1974, quando seu corpo ainda fazia parte do acervo público de um museu francês. Nessas exposições, Sarah era exposta seminua, medida, observada e analisada e comparada ao homem branco ocidental que tomava a si mesmo como o símbolo máximo de humanidade e civilização. Sarah era mais uma negra classificada como exótica.

I94 ] Considerações finais

Em sintese, sublinha-se a importância dos estudos sobre a moda tentando demonstrar o quanto eles se configuram como um frutifero campo de pesquisa para as Ciências Sociais. Por meio de uma breve análise do termo exótico, podemos concluir que ele guarda em si relações semelhantes nesse campo e nos saberes antropológicos. Em ambos, a construção do significado de exótico exige o contato e a sobreposição de mundos diferentes. Para Leitão (2007, p. 213), "o exótico está sempre situado, não no absoluto desconhecimento, mas na tensão entre conhecido e desconhecido, entre próximo e distante". Conforme Todorov (2005), no exotismo, o que é valorizado não é propriamente 0 outro, mas um ideal que funciona tal qual a crítica de sua cultura de referência. Logo, reside uma perspectiva etnocêntrica no sentido de eleger sua própria cultura como o parâmetro único e absoluto de valor no ato de comparação com as demais culturas - se é exótico em relação a mim, às minhas caracteristicas e à minha lógica estética. As diferenças entre nós e os outros são confirmadas e restabelecidas, como foi percebido.

No que tange ao campo de pesquisa realizado na agência Belas Modelos e à literatura especifica sobre moda, revela-se que o universo da moda resguarda traços de relações baseadas no modelo centro-periferia, no qual se percebe a importância das modelos estrangeiras, a necessidade de se adequarem aos padrões de beleza ditados pela Europa e a relevância do Sudeste e Sul do Brasil como grandes centros produtores e difusores da moda nacional, entre outras evidências. 
Uma análise mais aprofundada de nossa própria linguagem traz ainda importantes insights no sentido de revelar as relações de poder subscritas nas dinâmicas sociais baseadas na lógica estética do universo da moda. Rivera (2010) afirma que, no colonialismo, as palavras têm uma função muito peculiar: elas não designam quando não encobrem. Dessa forma, a escrita, sendo passivel de um controle colonial, marca relações de dominação/submissão que podem passar despercebidas pelos nossos cotidianos movimentos automáticos de fala e escuta.

Assim, conclui-se que as concepções de corpo ideal e beleza, além da forma como tais concepções são relacionadas, indispensáveis nos escritos apresentados, são produções históricas, sociais e culturais produzidas e reproduzidas por diferentes mecanismos sociais, politicos e culturais que atuam no sentido de naturalizar ou questionar as normas vigentes. A moda é uma dessas instituições que opera nesse sentido: construir e reconstruir os padrões corporais, as representações de beleza e do que é exótico presentes na sociedade atual.

Recebido em: 15-10-2017

Aprovado em: 05-02-2018

\section{NOTAS}

${ }^{1}$ É bem verdade que a Antropologia amadureceu epistemologicamente e hoje entendemos que o exercício da alteridade, bem como essa distância necessária para o estranhamento, não necessita ser geográfica, mas de ordem psíquica, como defende Peirano (1999). Entretanto, reflete-se até que ponto o rótulo de exótico sobrevive nos dias atuais escondendo formas veladas de relações racistas perpetuadas em nossa sociedade.

2 Segundo Büest (2006), a top model é um dos agentes mais importantes no trabalho de produção, circulação, promoção, divulgação e/ou publicidade que consagra a autoridade do estilista ou da marca ali expostos. 0 papel das top models é incorporar o humor das roupas e da coleção, incorporar o ideal de mulher e de beleza que cada marca contratada deseja mostrar. A questão da mobilidade e da ascensão social também deve ser sublinhada não somente por causa da remuneração, mas também do prestígio que ela oferece. Esse fator, segundo Pereira (2004), reforça o desejo das adolescentes que almejam seguir a profissão. Observando as entrevistas, percebe-se que as modelos da Belas Modelos não atentaram tanto para a questão da ascensão financeira. Raríssimas exceções da Belas Modelos conseguiram trabalho e sucesso o suficiente para mudarem suas condições de vida. No entanto, as modelos sempre salientaram o status e o prestígio social que essa profissão lhes confere. Ser reconhecida na cidade ou no colégio como modelo, acreditar que sua profissão é sinônimo de glamour e ter orgulho em ser capa de revistas foram alguns relatos que sinalizam esse sentido.

${ }^{3}$ Informações retiradas do livro Profissão modelo:em busca da fama, de Margareth Libardi, publicado pela editora Senac e lançado em 2004.

${ }^{4}$ Apesar de não ter sido enfatizada da maneira que se gostaria pelos próprios limites do artigo, a questão de gênero apareceu no campo quando percebemos o destaque maior delegado à modelo negra Ana Braga tanto em relação às outras modelos quanto aos dois outros modelos africanos. A categoria do exótico sempre foi relacionada a ela de maneira mais forte. Por essa questão, a última parte do artigo foi dedicada a cruzar a questão racial com a de gênero ainda que de maneira breve.

\section{REFERÊNCIAS}

ARRAES, Jarid. A carne mais exótica do mercado, 2013. Disponível em: <http://blogueirasnegras. org/2013/07/22/a-carne-mais-exotica-do-mercado/>. Acesso em: 6 out. 2017.

BONADIO, Maria Claudia. Dignidade, celibato e bom comportamento: relatos sobre a profissão de modelo e manequim no Brasil dos anos 1960. In: Cadernos Pagu, Campinas, jan./jun., 2004, n. 22 , pp. 47-81.

BÜEST, A. A. N. 0 ritual do desfile de moda na sociedade tecnológica: uma abordagem etnográfica. Curitiba, 2006. Dissertação (Mestrado em Tecnologia) - Centro Federal de Educação Tecnológica do Paraná. 
CASTRO, Ana Lúcia de. Culto ao corpo e sociedade: mídia, estilos de vida e cultura de consumo. 2. ed. São Paulo: Annablume, Fapesp, 2007.

DAVIS, Angela. Mulher, raça e classe. Tradução livre. Plataforma Gueto_2-13. Disponivel em: <https:// we.riseup.net/assets/165852/mulheres-rac3a7a-e-classe.pdf >. Acesso em: 14 fev. 2018.

GODELIER, Maurice. Ocidente, um espelho partido. Reunião Nacional da Anpocs, 16, 1992, Caxambu. Disponivel em: <http://www.anpocs.org.br/portal/publicacoes/rbcs_00_21/rbcs21_01.htm>. Acesso em: 2 abr. 2014.

LE BRETON, David. A sociologia do corpo. Petrópolis, RJ: Vozes, 2006.

LEITÃO, Débora Krischke. Nós, os outros: construção do exótico e consumo de moda brasileira na França. In: Horiz. antropol., Porto Alegre, v. 13, n. 28, pp. 203-230, dez. 2007. Disponivel em: <http://www.scielo.br/ scielo.php?script=sci_arttextEtpid=S0104-71832007000200009EtIng=enEtnrm=iso>. Acesso em: 13 out. 2017.

LIBARDI, Margareth. Profissão modelo: em busca da fama. São Paulo: Senac, 2004.

LIPOVETSKY, Gilles. A terceira mulher: permanência e revolução do feminino. São Paulo: Companhia das Letras, 2000.

MALINOWSKI, Bronislaw. Argonautas do Pacífico ocidental: um relato do empreendimento e da aventura dos nativos nos arquipélagos da Nova Guiné Melanésia. 3. ed. São Paulo: Abril Cultural, 1984. 424 p. (Os Pensadores).

MARTINEZ, Fabiana J. 0 espelho de Narciso: corpos e textos do consumo. Campinas, 2003. Dissertação (Mestrado) - Instituto de Filosofia e Ciências Humanas. Universidade Estadual de Campinas, Unicamp.

De menina a modelo, entre modelo e menina: gênero, imagens e experiência. Campinas, 2009. Tese (Doutorado) - Instituto de Filosofia e Ciências Humanas. Universidade Estadual de Campinas, Unicamp.

PEIRANO, Mariza G. S. A alteridade em contexto: a antropologia como ciência social no Brasil. Brasilia: UnB, 1999.

PEREIRA, Cláudia da Silva. Fabricando sonhos: ascensão social no mercado da moda. In: RIMAR - Revista Interdisciplinar de Marketing, v. 3, n. 1, 2004. Disponivel em: < http://www.rimar-online.org/artigos/ v3n1a4.pdf >. Acesso em: 3 set. 2010.

RIBEIRO, Djamila. Racismo: manual para os sem-noção I. In: Carta Capital, jun. 2017. Seção Sociedade. Disponivel em: <https://www.cartacapital.com.br/revista/957/racismo-manual-para-os-sem-nocao-i>. Acesso em: 23 fev. 2018.

SILVA, Bruno G.M.,FREIRE, Maíra S. de L Os estudos pós-coloniais, a antropologia e o sujeito subalterno. In: Revista Equatorial, Natal, n. 1, pp. 47-63, 2013. Disponivel em: https://incubadora.ufrn.br/index.php/ equatorial/article/view/1652/pdfs. Acesso em: 18 fev. 2018.

RIVERA CUSIQANOI, Silvia. Ch'ixinakax utxiwa: una reflexión sobre prácticas y discursos descolonizadores. Buenos Aires: Tinta Limón, 2010, 80 p.

TODOROV, Tzvetan. Nosotros y los otros. Buenos Aires: Siglo XXI, 2005.

TROUILLOT, Michel-Rolph. Anthropology and the savage slot: The poetic and politics of otherness. In: Global transformations: Anthropology and the modern world. New York, Palgrave Macmillan, 2003. 